\title{
First results from a rotational Raman scattering cloud algorithm applied to the Suomi National Polar-orbiting Partnership (NPP) Ozone Mapping and Profiler Suite (OMPS) Nadir Mapper
}

\author{
A. Vasilkov ${ }^{1}$, J. Joiner ${ }^{2}$, and C. Seftor ${ }^{1}$ \\ ${ }^{1}$ Science Systems and Applications Inc., Lanham, MD, USA \\ ${ }^{2}$ NASA Goddard Space Flight Center, Greenbelt, MD, USA
}

Correspondence to: A. Vasilkov (alexander.vasilkov@ssaihq.com)

Received: 5 February 2014 - Published in Atmos. Meas. Tech. Discuss.: 19 March 2014

Revised: 28 July 2014 - Accepted: 13 August 2014 - Published: 10 September 2014

\begin{abstract}
This paper reports initial results from an Ozone Mapping and Profiler Suite (OMPS) Nadir Mapper cloud pressure and cloud fraction algorithm. The OMPS cloud products are intended for use in OMPS ozone or other tracegas algorithms. We developed the OMPS cloud products using a heritage algorithm developed for the Ozone Monitoring Instrument (OMI) on NASA's Aura satellite. The cloud pressure algorithm utilizes the filling-in of ultraviolet solar Fraunhofer lines by rotational Raman scattering. The OMPS cloud products are evaluated by comparison with OMI cloud products that have been compared in turn with other collocated satellite data including cloud optical thickness profiles derived from a combination of measurements from the CloudSat radar and MODerate-resolution Imaging Spectroradiometer (MODIS). We find that the probability density functions (PDFs) of effective cloud fraction retrieved from OMPS and OMI measurements are very similar. The PDFs of the OMPS and OMI cloud pressures are comparable. However, OMPS retrieves somewhat higher pressures on average. The current NASA total ozone retrieval algorithm makes use of a monthly gridded cloud pressure climatology developed from OMI. This climatology captures much of the variability associated with the relevant cloud pressures. However, the use of actual cloud pressures retrieved with OMPS in place of the OMI climatology changes OMPS total column ozone estimates locally (presumably in the correct direction) only in areas with large differences between climatological and actual cloud pressures. The ozone differences can be up to $5 \%$ in such areas.
\end{abstract}

\section{Introduction}

The Ozone Mapping and Profiler Suite (OMPS), flying on the Suomi National Polar-orbiting Partnership (NPP) satellite, launched by the US National Aeronautics and Space Administration (NASA) on 28 October 2011, consists of two nadir sensors and a limb profiler. The OMPS nadir sensors, the Nadir Mapper (NM) and the Nadir Profiler (NP), are designed to provide operational retrievals of total column ozone and ozone profiles. In the initial ground processing design phase, cloud pressure was not envisaged to be an operational OMPS product; it was planned that cloud information from the Visible Infrared Imaging Radiometer Suite (VIIRS) would be utilized within the ozone algorithms.

Following the conception of the initial OMPS ozone algorithms, much has been learned about how clouds behave with respect to solar backscatter measurements such as those from OMPS. The launch of the Ozone Monitoring Instrument (OMI) on NASA's Aura satellite within the "A-Train" (Afternoon Train) Constellation has provided a unique opportunity to compare cloud pressures derived from solar backscatter measurements with other nearly coincident cloud measurements including cloud optical thickness profiles retrieved from the CloudSat radar and MODerate-resolution Imaging Spectroradiometer (MODIS) radiances. For example, it is now clear that cloud pressures derived from solar backscatter measurements (henceforth referred to as cloud optical centroid pressures or OCPs) are appropriate for use in tracegas retrievals from similar instruments (e.g., Vasilkov et al., 2004; Joiner et al., 2009); cloud top pressures (CTPs) derived from thermal measurements are not equivalent to OCPs and 
do not provide good estimates of solar photon path lengths through clouds that are needed for trace-gas retrievals from ultraviolet and visible wavelength solar backscatter measurements (Joiner et al., 2006; Vasilkov et al., 2008; Ferlay et al., 2010; Joiner et al., 2012). The cloud OCP can be thought of and modeled as a reflectance-averaged pressure level reached by backscattered photons (Joiner et al., 2012). As clouds are vertically inhomogeneous, the OCP will not necessarily be in the geometrical center of the cloud, but rather in the socalled optical centroid of the cloud (Vasilkov et al., 2008; Ziemke et al., 2009; Joiner et al., 2012); this is why we refer to the pressure as OCP. Cloud pressure information from solar backscatter measurements can be used to detect multilayer clouds either alone (Rozanov et al., 2004) or in combination with thermal infrared measurements (Joiner et al., 2010).

The current NASA OMPS total ozone algorithm (McPeters et al., 2013) makes use of a monthly gridded climatology of cloud OCP derived from OMI rotational Raman scattering (RRS) retrievals. In this work, we apply the OMI RRS algorithm to OMPS radiances. Although the OMPS and OMI instruments are similar in some respects, there are substantial differences in the detailed specifications of these instruments including spectral and spatial resolutions. It was not clear at the onset whether OMPS would achieve the same level of performance as OMI with respect to the RRS cloud retrieval. We evaluate the OMPS cloud retrievals by comparison with OMI. Since the instruments are in similar but not identical orbits, we compare the retrieved cloud parameters using probability distribution functions. We then examine whether simultaneously derived cloud OCPs from OMPS improve total column ozone retrievals as compared with the use of the OMI cloud climatology. A goal of the paper is to demonstrate that a cloud algorithm first designed for a high spectral resolution instrument like OMI can be applied to a lower-resolution instrument like OMPS and that the OMPS cloud products have sufficient quality to be used in operational OMPS trace-gas algorithms. We also document several instrumental issues that are important for others who may process OMPS data.

The paper is structured as follows: following a brief description of the OMPS NM instrument in Sect. 2, Sect. 3 reports details of the development of the OMPS RRS cloud algorithm. Section 4.1 describes the evaluation of the OMPS cloud products. Effects of the use of actual OMPS-derived cloud OCPs on total column ozone retrievals are shown in Sect. 4.2. Conclusions are given in Sect. 5.

\section{The OMPS Nadir Mapper (NM)}

The OMPS NM employs a 2-D charge-coupled device (CCD) that samples spectrally in one dimension and spatially in the other. It has spectral coverage from 300 to $380 \mathrm{~nm}$. The spectral bandpass has a full-width at half maximum
(FWHM) of $\sim 1.0 \mathrm{~nm}$ and the sampling is $0.42 \mathrm{~nm}$ (Flynn et al., 2006). The optical projection onto the CCD creates a "spectral smile" across the CCD where, for a given spatial row, the wavelength changes by approximately $0.2 \mathrm{~nm}$ from one edge of the CCD to the center, then approximately $0.2 \mathrm{~nm}$ back to the other edge. The spectral bandpass also varies across the swath. For comparison, OMI has spectral coverage from $270-500 \mathrm{~nm}$ with a FWHM of $\sim 0.5 \mathrm{~nm}$ and a spectral smile on the order of $2.0 \mathrm{~nm}$ from the edge to the center of the CCD and back to the other edge (Levelt et al., 2006).

The OMPS NM has a $2800 \mathrm{~km}$ swath width. It has a nadir footprint of $50 \mathrm{~km} \times 50 \mathrm{~km}$ in its nominal configuration and 36 pixels in the cross-track dimension. The satellite motion provides spatial sampling in the along track direction. The spatial sampling in the across and along track directions can be adjusted. During the instrument commissioning phase, the instrument was operated at its highest possible spatial resolution $(\sim 2.5 \mathrm{~km}$ across track $\times 10 \mathrm{~km}$ along track); now once per week, the instrument is operated in a high spatial resolution mode $(10 \mathrm{~km} \times 10 \mathrm{~km})$. In this work, we focus on data from the nominal operating mode. The OMI swath width for comparison is $2600 \mathrm{~km}$, and it provides 60 pixels in the cross-track direction with a nadir footprint size of $\sim 12 \mathrm{~km} \times 24 \mathrm{~km}$.

\section{OMPS RRS cloud algorithm}

\subsection{Basic approach}

Our OMPS cloud algorithm is essentially a slightly modified version of an algorithm that was developed for OMI as described in Joiner et al. (2004), Joiner and Vasilkov (2006), and Vasilkov et al. (2008). The algorithm uses the mixed Lambert-equivalent reflectivity (MLER) concept that treats both cloud and ground as horizontally homogeneous opaque Lambertian-reflecting surfaces (McPeters et al., 1996; Ahmad et al., 2004; Stammes et al., 2008). The measured topof-the-atmosphere (TOA) radiance (normalized by the solar flux), $I_{m}$, is calculated as a sum of the clear-sky and overcast (cloudy) sub-pixel radiances, $I_{\mathrm{g}}$ and $I_{\mathrm{c}}$, respectively, weighted by an effective cloud fraction $f$, i.e.,

$I_{m}=I_{\mathrm{g}}\left(R_{\mathrm{g}}\right) \times(1-f)+I_{\mathrm{c}}\left(R_{\mathrm{c}}\right) \times f$,

where $R_{\mathrm{g}}$ and $R_{\mathrm{c}}$ are the ground and cloud Lambertianequivalent reflectivities, respectively. $R_{\mathrm{c}}$ is assumed to be $80 \%$; the same assumption is used in the OMPS total column ozone algorithm. This value produces the observed amount of Rayleigh scattering (Ahmad et al., 2004) or atmospheric absorption (Koelemeijer et al., 2001) within the context of the MLER model. $R_{\mathrm{g}}$ is taken from a climatology developed from Total Ozone Mapping Spectrometer (TOMS) data with correction for areas of sunglint (C. Ahn, personal communication, 2009). 
The first step in the cloud retrieval is to determine $f$ by inverting Eq. (1) at a wavelength not substantially affected by rotational Raman scattering or atmospheric absorption $(354.1 \mathrm{~nm})$. We then retrieve the cloud OCP using the measured amount of filling-in and depletion of solar Fraunhofer line structure caused by RRS. Cloud pressure is derived from the high-frequency structure of the normalized radiance caused by RRS on molecules in the atmosphere. RRS is an inelastic process that redistributes energy between spectral points. RRS produces a filling-in effect within the core of solar Fraunhofer lines and can produce a depletion-type effect in the spectral peaks in the wings of the lines. To describe this effect quantitatively, Joiner et al. (1995) introduced a quantity called a "filling-in factor" that was defined as a percentage ratio of the difference between the total scattered radiance (i.e., measured radiance) and elastically scattered radiance to the elastically scattered radiance. The filling-in factor can be negative at wavelengths where the depletion effect occurs. We will use the filling-in factor term or simply "fillingin" to describe the RRS effect.

Clouds screen the atmosphere below and thus reduce RRS in the entire atmosphere and therefore the amount of fillingin of Fraunhofer lines. This reduction of the filling-in as compared with clear skies is related to the cloud pressure. Joiner et al. $(1995,2004)$ showed that the amount of the filling-in is approximately proportional to a pressure level at which a cloud, treated as a Lambertian surface in our approach, is placed. This proportionality is observed from the surface to top of the troposphere (from 1000 to $100 \mathrm{hPa}$ ) for solar zenith angles less than $80^{\circ}$. The cloud OCP is derived by a minimum-variance spectral fitting technique that minimizes the differences between the observed and computed high-frequency structure of TOA reflectance in the 345.5$354.5 \mathrm{~nm}$ range.

\subsection{Rotational Raman scattering}

The RRS spectral effects decrease with instrument spectral resolution. The OMPS NM sensor has a lower spectral resolution than the OMI. Therefore, the OMPS $\mathrm{SO}_{2}$ and $\mathrm{O}_{3}$ algorithms are less sensitive to effects of RRS than their OMI counterparts. The cloud OMPS RRS algorithm will also be less sensitive to cloud pressure than OMI for a given signalto-noise ratio.

Figure 1 compares the computed filling-in at the OMI and OMPS spectral resolutions. We compute inelastic RRS using the LInearized Discrete Ordinate Radiative Transfer (LIDORT-RRS) code (Spurr et al., 2008). LIDORT-RRS allows for accurate radiative transfer (RT) calculations in the presence of cloud/aerosol scattering. The RT computations were done for a solar zenith angle (SZA) of $45^{\circ}$, observation at nadir, and surface albedo of 0.05 . Figure 1 clearly shows that the OMI filling-in is significantly higher than that computed at the OMPS resolution. However, even at the OMPS spectral resolution, the RRS filling-in is not negligible.

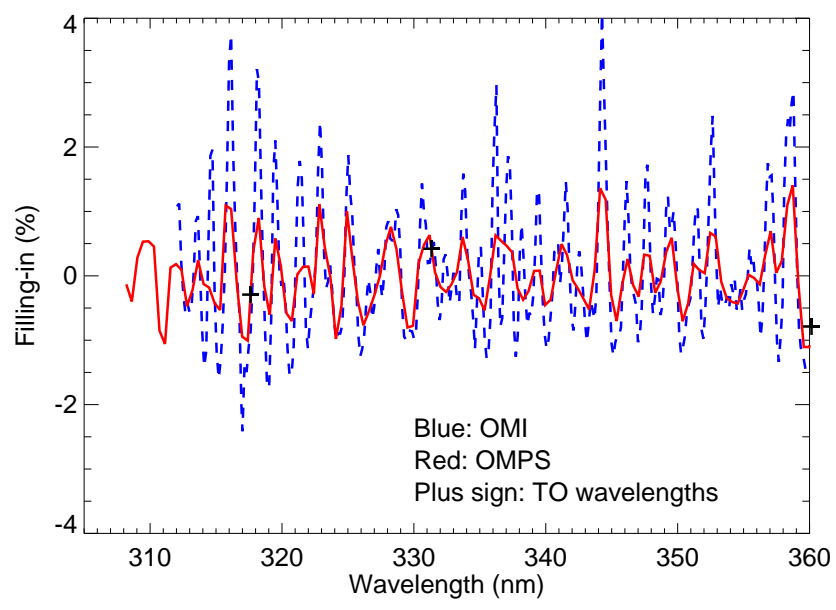

Figure 1. Comparison of OMI and OMPS RRS filling-in. Plus signs show the wavelengths used in the OMPS total ozone (TO) algorithm.

To compute the spectral effects of RRS, we use the fast table lookup approach that is implemented in the OMI algorithm and based on the approach of Joiner et al. (1995). In this approach, the fractional amounts of the various components of the radiance (according to a Lambertian surface model) are computed and stored for each iteration of scattering for a range of satellite and solar zenith angles, azimuth angles, and wavelengths (see Eq. 31 in Joiner et al., 1995). These radiance components are then linearly interpolated between nodes of the table. The radiative transfer calculations are carried out with the TOMRAD (TOMS RADiative transfer model) code based on successive iterations of the auxiliary equation in the theory of radiative transfer (Dave, 1964). The dependence upon surface reflectivity can be accounted for on the fly as described in Joiner et al. (1995) (see Eq. 31) and eliminates the need for an additional dimension in the table. This significantly reduces the amount of interpolation (and thus computational expense) needed for the table lookup approach.

Because the table parameters vary slowly and smoothly with wavelength, it is not necessary to provide them at high spectral resolution or sampling. The dependence of RRS filling-in on spectral resolution is accounted for by generating a secondary table for each individual instrument of the single scattered filling-in based on its measured solar irradiance spectrum as outlined in Joiner et al. (1995). In this approach, explicit knowledge of the instrument slit response function is not needed.

\subsection{Detailed approach}

While the determination of both the effective cloud fraction and OCP uses normalized Sun-normalized radiances, the construction of a lookup table for RRS filling-in requires the use of a measured or estimated solar spectrum. For OMPS, 
the measurement requirement for solar irradiance and normalized radiance differ substantially (see below). Because we require both normalized radiance measurements and irradiance spectral estimates, we examined both from OMPS. Here, we detail our findings that lead to the use of a synthetic solar spectrum in place of a measured solar spectrum; this is a change from our application to OMI that used a measured solar spectrum.

Figure 2 (top) shows the post-launch solar flux measurement from the OMPS NM sensor for the wavelength region used in our RRS cloud OCP retrieval. This measurement represents the average values of a series of solar flux measurements for the 36 cross-track fields of view (FOVs) taken every week during the first year of observation; since no discernible degradation in the diffuser was seen during this time period, the average provides a representative set of solar irradiance values. In deriving the average, the Sun-Earth distance was accounted for, and the resulting measurement was normalized to 1 astronomical unit (AU). Additionally, because the solar flux is taken off a diffuser that is stepped over seven different positions in order to illuminate the full CCD, measurements from the seven different positions had to be stitched together using data from overlapping illuminated regions for each position. A circular (loop) pattern is clearly evident in the measurements shown in Fig. 2. This pattern is due to combination of the spectral smile mentioned earlier, the change in bandpass across the CCD, and the accuracy of the irradiance measurements themselves.

If there were no spectral smile, each of the 36 FOVs would measure irradiance at the same 196 wavelengths. Furthermore, if, for a given wavelength, the bandpass was the same for each FOV, we would expect to see irradiance measurements corresponding to 196 wavelengths from 300 to $380 \mathrm{~nm}$; assuming no error in the measurements, each FOV would measure the same irradiance for each wavelength, and we would see a set of 196 points. Because of the spectral smile, the measurements do not correspond to a set of 196 wavelengths but are spread across an interval corresponding the smile $( \pm 0.2 \mathrm{~nm})$ about each of the 196 wavelengths at the center of the CCD, and the measured irradiance are spread out over the entire 300 to $380 \mathrm{~nm}$ range. The loops seen in the measurement are due to a combination of bandpass changes across the FOV and errors in the irradiance measurements from the different FOVs.

To further separate effects due to the change in bandpass from errors inherent in the measurements themselves, we produced a synthetic OMPS solar irradiance spectrum by convolving a high-resolution solar spectrum (Chance and Kurucz, 2010) with the wavelengths and bandpasses measured before launch for each cross-track FOV. The expected OMPS solar flux is shown in Fig. 2 (bottom) using dots for each cross-track position. The small loop pattern seen in this figure is solely due to the fact that, for a given wavelength, the bandpass changes across the CCD and, therefore, is different for each FOV. We should emphasize that if the bandpass did
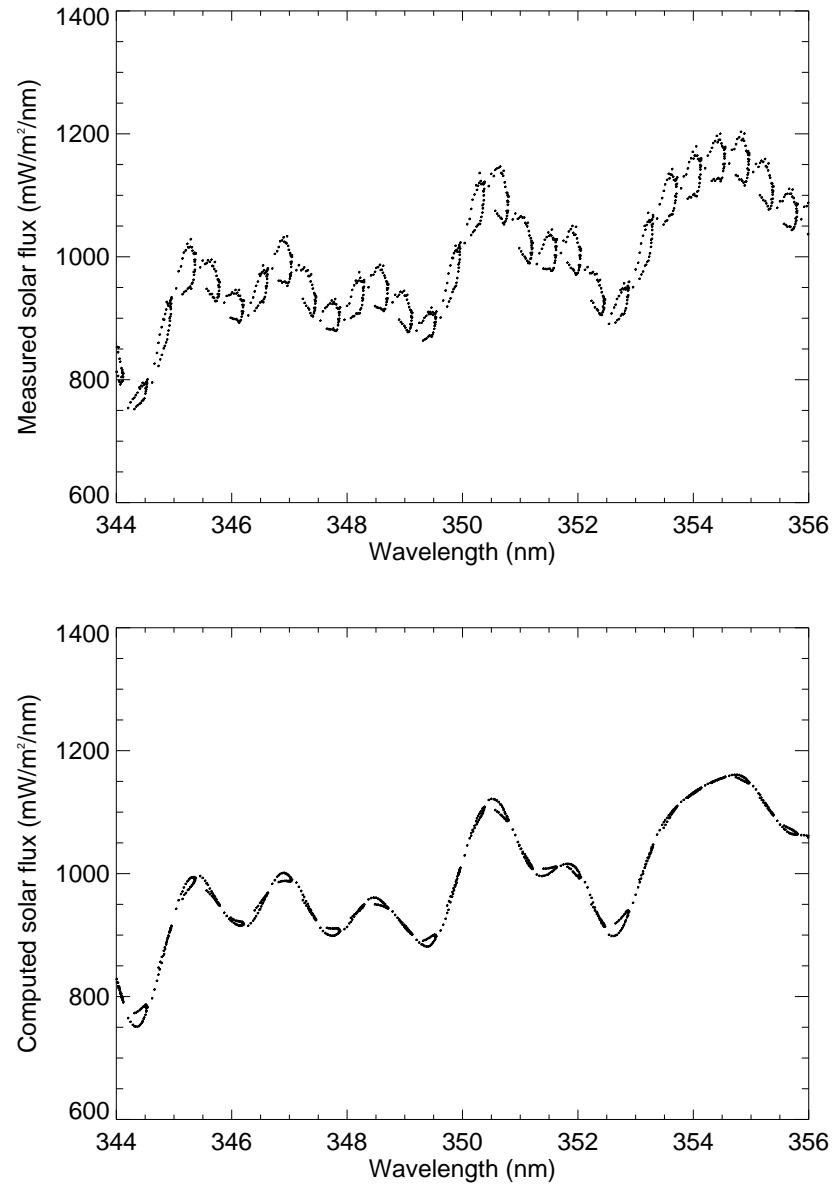

Figure 2. OMPS-measured solar flux (top) and high-resolution solar flux convolved with the measured OMPS NM bandpasses (bottom). Dots are for different cross-track positions. Note that many dots (due to the spectral smile) can fuse together to visually simulate a line.

not change, we would not see a loop pattern at all but, rather, a smooth irradiance spectrum from 300 to $380 \mathrm{~nm}$ that reflects the spectral smile.

A comparison of the calculated with measured solar flux indicates that the larger loop pattern seen in the measurement is mostly a reflection of the relatively lax $7 \%$ pre-launch specification for irradiance accuracy. We also note that the pre-launch specification for radiance measurements was a similarly lax $8 \%$. It should be noted that the radiance and irradiance measurements are designed to be used together, as the ratio of radiance to irradiance, to form a normalized radiance. Since the solar diffuser precedes the same optics used in the Earth radiance measurements, many systematic errors, including sensor effects such as spectral smile, cancel in the normalized radiance, and a stricter pre-launch specification of $2 \%$ was therefore placed on this quantity. Post-launch analysis performed with the OMPS NM sensor indicates that the normalized radiance generally falls within this specification (Seftor et al., 2014). This analysis also shows a shift 
$(0.06 \mathrm{~nm}$ or less $)$ in wavelength between the radiance and irradiance measurements that, if left uncorrected, will cause errors in the normalized radiance. We account for this shift through a term in our fitting algorithm; results from this term agree well with results shown in Seftor et al. (2014). Furthermore, analysis of the resulting Level 2 ozone products validate their performance as well (Kramarova et al., 2013).

We attempted cloud OCPs retrievals using secondary RRS filling-in lookup tables computed with both the measured and synthetic solar spectra. We obtained superior results using the tables generated with the synthetic solar spectrum because the sensor characteristics (including calibration errors) discussed above were not taken out of the measured solar flux. Cloud pressure retrievals with the lookup tables generated with the measured solar spectrum exhibited more artifacts, e.g., negative values of retrieved OCPs, than with the tables generated using the synthetic spectrum. Therefore, all results shown here are derived using the tables generated with the synthetic solar spectra.

Other modifications to the original OMI RRS algorithm were needed in order to obtain comparable results. For example, OMPS has a more coarse wavelength sampling as compared with OMI. The use of a spline scheme for the interpolation of the radiance and irradiance data to the table wavelength grid was needed for OMPS, whereas a faster linear scheme can be used for OMI. A key element of the RRS cloud algorithm is a so-called soft calibration of measured TOA radiances. A general approach to the soft calibration is to use a radiative transfer model to compute radiances for scenes where we assume that all parameters are known. As has been done with OMI, we select pixels over highly reflecting ice-covered land in Antarctica where reflectivities are relatively constant. In particular, the Antarctic plateau region has very high surface reflectivity, low aerosol loading during quiescent periods, and very small amounts of cloud cover. Here, we use 1 day of data near solstice in December 2012 to compute the spectral radiance residuals (i.e., observed minus computed filling-in) for OMPS.

Figure 3 shows spectral residuals for different cross-track positions. An overall envelope is apparent with a few positions having larger residuals at a few wavelengths. The envelope pattern in the residuals is due primarily to errors caused by interpolating the OMPS normalized radiances to the predefined table wavelengths. Note again that the OMPS wavelengths vary as a function of cross-track position. Similar patterns are seen in OMI-derived radiance residuals (Joiner and Vasilkov, 2006).

\section{Results}

\subsection{Comparison of OMI and OMPS cloud products}

Figure 4 (top) shows a map of cloud OCPs retrieved from OMPS measurements on 7 January 2013. Data with effective

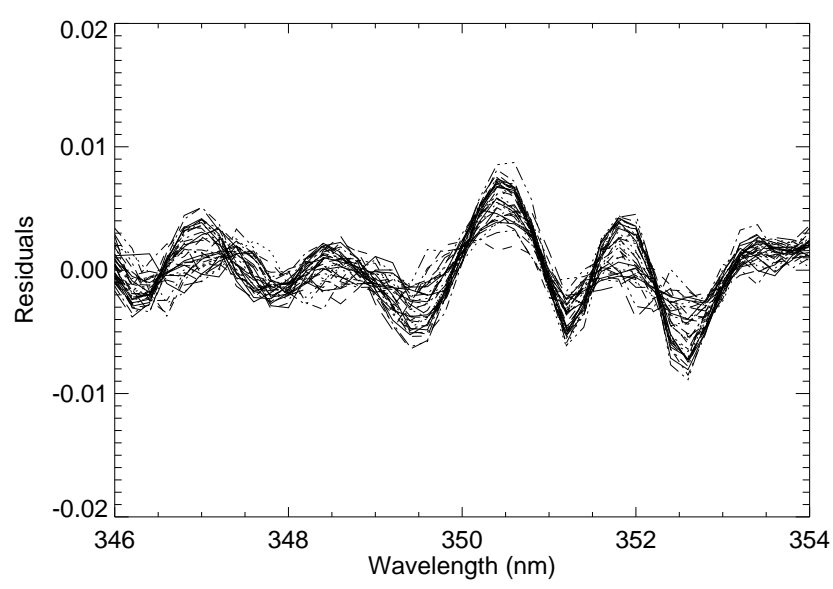

Figure 3. Spectral residuals/corrections that are applied to measured TOA OMPS radiances as derived from data over Antarctica. Each curve is for a particular OMPS cross-track position.

cloud fraction greater than 0.05 are shown, as cloud pressure retrievals are not performed for cloud fractions $<0.05$. Similarly, Fig. 4 (bottom) shows a map of cloud OCP retrieved from OMI measurements on the same day. OMI data affected by so the called "row anomaly" were removed. The row anomaly affects the quality of the level $1 \mathrm{~b}$ radiance data for particular viewing directions of OMI (cross-track positions) and consequently the cloud products for those cross-track positions. More information about the OMI row anomaly can be found at http://www.knmi.nl/omi/research/product/ rowanomaly-background.php. A visual comparison of two maps suggests that there is good qualitative agreement between the spatial distribution of OCP derived from OMI and OMPS. For instance, areas with high-altitude clouds over the northern part of the Pacific, Mexico, northern part of the Atlantic Ocean, northern China, etc., look quite similar. However, there are some quantitative differences, for instance, in the oceanic tropics where OMI displays more low pressure OCPs than OMPS.

Figure 4 (top) shows that the rightmost OMPS swath position has a significant error (unrealistically low cloud pressures). The precise cause of this error is related to an insufficient number of OMPS pixels in the rightmost swath position available for soft calibration over the Antarctic plateau near solstice.

To compare the cloud products retrieved from OMPS and OMI quantitatively, we use probability density functions (PDFs) of effective cloud fraction (ECF) and OCP calculated for different latitude and ECF bins. A collocation of OMI pixels to OMPS pixels is not possible; therefore, we do not provide scatter plots. OMI flies at $705 \mathrm{~km}$ altitude; OMPS is at $824 \mathrm{~km}$ altitude. Although they have roughly the same local equator crossing time, the difference in altitude means that they have coincident orbits on the Earth's surface every 


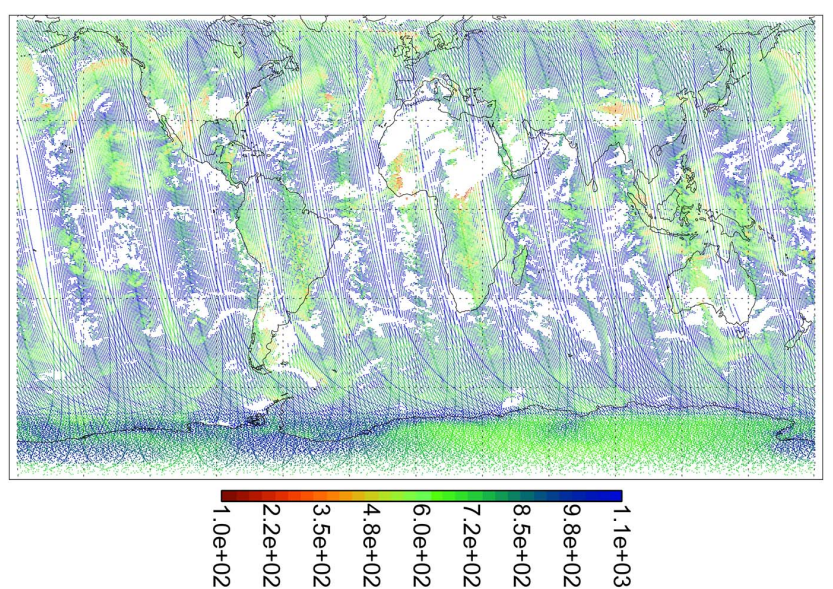

OMPS Cloud Pressure (hPa)

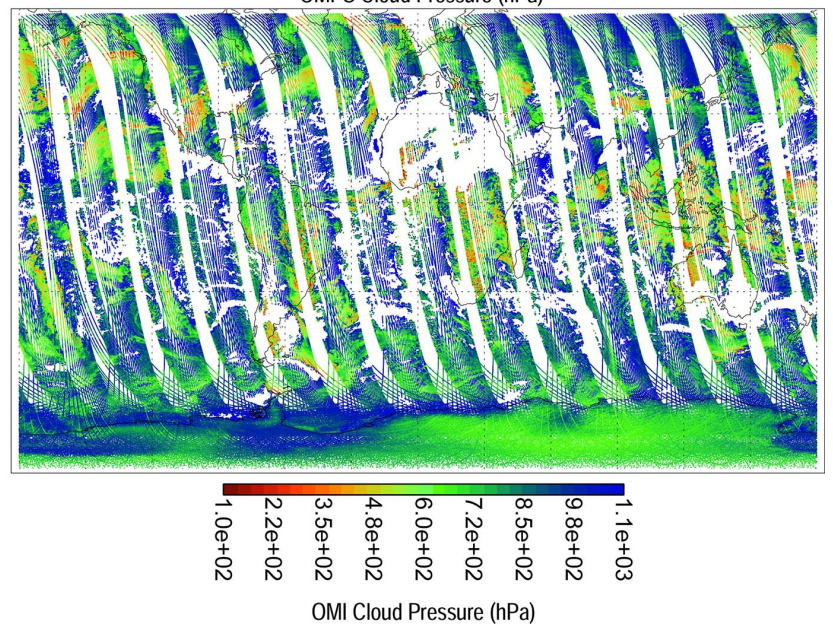

Figure 4. OCP (in hPa) from OMPS measurements (top) and OMI measurements (bottom) on 7 January 2013. Every pixel on the maps is represented by a color dot. OMI has 60 cross-track pixels while OMPS has 36 pixels. More pixels leads to a visual effect of the OMI map being brighter than the OMPS map.

8 days or so. And, even though the orbit can coincide, the times and spatial resolutions are still somewhat different.

Figure 5 shows a comparison of PDFs of OMPS and OMI effective cloud fractions for the tropics. It should be noted that the ECF values in Fig. 5 start at the zero value even though we do not report OCPs for ECF $<0.05$ because of substantially increasing errors in OCP with decreasing ECF. The PDFs of OMPS and OMI effective cloud fractions are practically identical for ECFs higher than approximately $0.1-0.2$. Even if we assume that radiometric calibration of both OMI and OMPS is perfect, we can expect differences in the derived ECFs owing to the different sizes of the OMI and OMPS footprints. It is reasonable to anticipate more cases of higher cloud fraction for the smaller OMI footprints. Indeed, noticeable differences are observed for low ECFs with more clear scene pixels for OMI than for OMPS because OMI has more smaller pixels. Small differences in the PDFs of ECFs

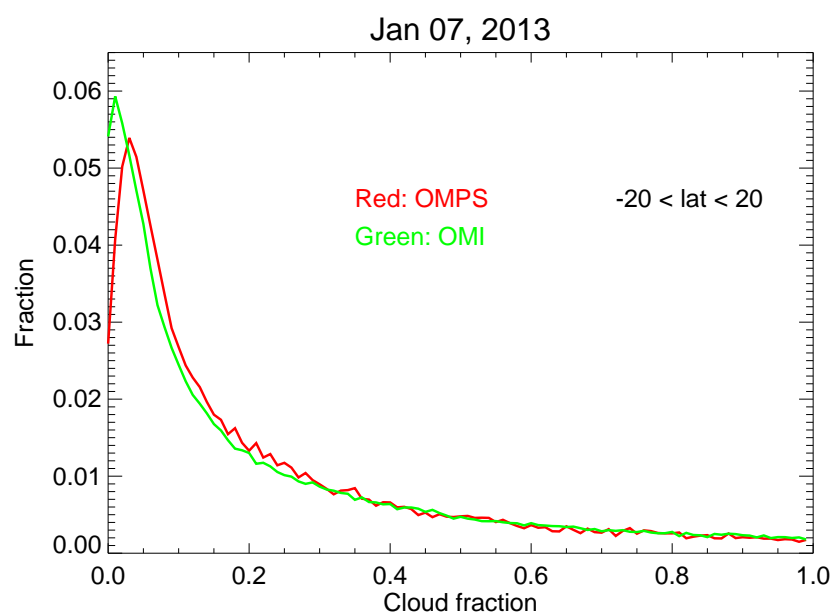

Figure 5. Probability density functions of OMPS and OMI effective cloud fractions for the tropics.

for ECF $>0.1-0.2$ could be explained by the fact that a significant fraction of the OMI smallest-size pixels near nadir are excluded from the comparison due to the row anomaly. Therefore, we compare PDFs of ECF for OMPS and OMI pixels with similar sizes.

Figure 6 shows a comparison of PDFs of OCP retrieved from OMI and OMPS over the tropics and northern and southern mid-latitudes for scenes with ECF $>0.3$. OMI pixels affected by the row anomaly were excluded from the comparison. The comparison of the PDFs is similar to that carried out in Joiner et al. (2012); it is intended to evaluate the OMPS OCP retrievals for moderately to highly cloudy conditions. In general, the PDFs from OMI and OMPS cloud pressures qualitatively agree. However, OMPS retrieves higher cloud pressures more often that OMI does. Particularly, this is true for the tropics. A simple visual comparison of the maps in Fig. 4 reveals lower OMI cloud pressures in the tropics.

A possible cause of higher cloud pressure retrieved by OMPS could be related to the effects of stray light contributions to TOA radiances in OMPS. The algorithm is not sensitive to radiometric calibration errors if they are spectrally smooth because the algorithm makes use of a polynomial fit similar to DOAS (Differential Optical Absorption Spectroscopy) algorithms. The algorithm is indeed sensitive to stray light. The TOA radiance measured by the OMPS NM sensor is not corrected for stray light contributions, whereas a stray light correction is applied for OMI. Stray light is an additive error to the measured TOA radiance and leads to erroneous filling-in of Earthshine Fraunhofer lines. Cloud pressures retrieved from Raman scattering are approximately proportional to the filling-in of solar Fraunhofer lines (Joiner et al., 1995). Stray light increases the filling-in; if not properly accounted for, stray light can thus lead to erroneous cloud pressures. 

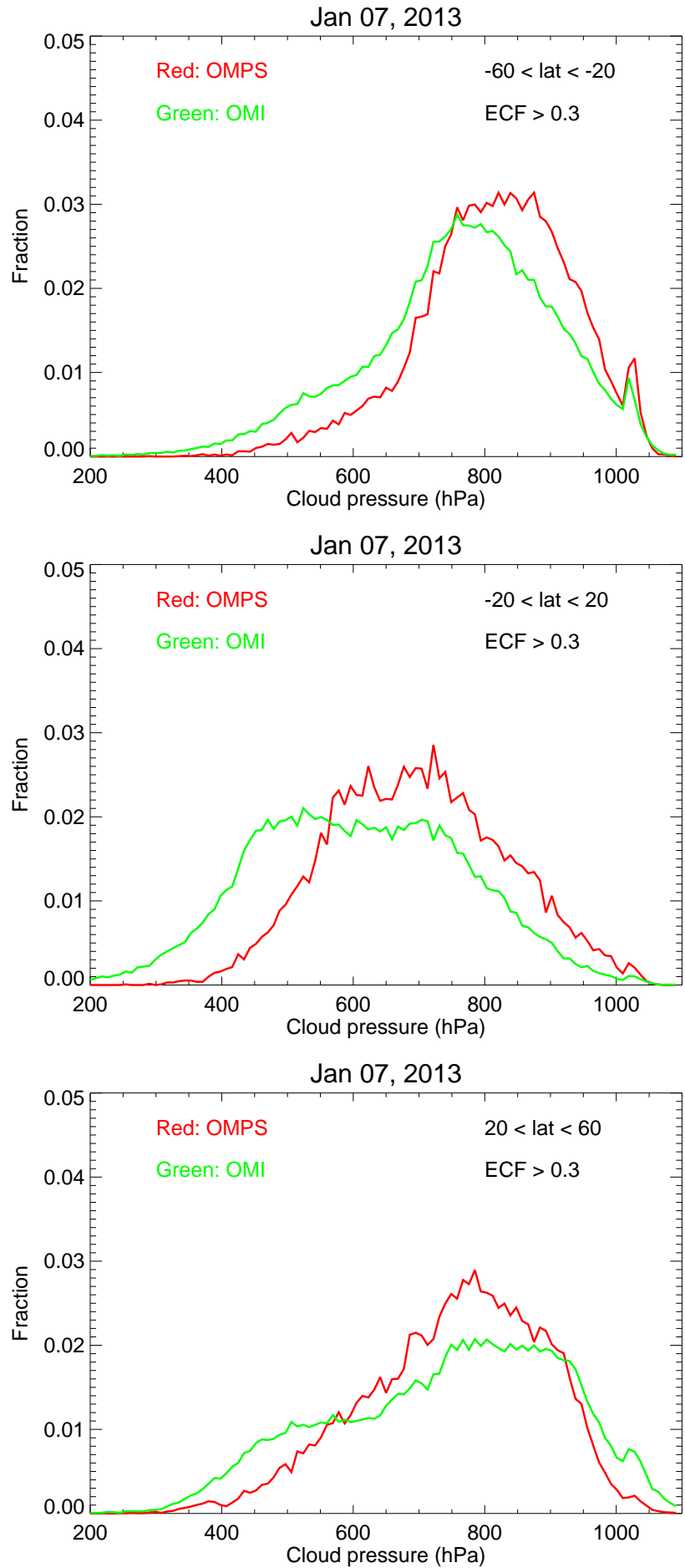

Figure 6. Probability density functions of OMPS and OMI cloud pressures for three latitude bins: southern mid-latitudes (top), tropics (middle), and northern mid-latitudes (bottom).

We ran an additional experiment using a version of the OMPS level $1 \mathrm{~b}$ data with a proposed stray light correction. We found that the PDFs were not substantially different from those in Fig. 6. This means that stray light in OMPS is likely not the root cause of the differences between OMPS and OMI cloud pressures.

OMI RRS OCP retrievals have also been compared with coincident OMI retrievals using oxygen dimer absorption (Sneep et al., 2008; Joiner et al., 2012) and predicted values based on a fast simulation using cloud optical thickness profiles derived from CloudSat radar reflectivity profiles and radiances from the MODerate-resolution Imaging Spectroradiometer (Vasilkov et al., 2008; Joiner et al., 2012). Although these comparisons were qualitatively good, some differences (within the range of the OMI and OMPS differences seen here) were noted. Those differences could be attributed to errors in the instruments and algorithms. Unfortunately, there is no clearly defined gold standard for validation. We similarly attribute the OMI-OMPS cloud pressure differences seen here to errors in the instruments and algorithms.

To evaluate the OMPS-derived OCP product, it is useful to analyze differences between surface pressure and OCP, $\Delta P=P_{\mathrm{s}}-P_{\mathrm{c}}$, for mostly clear-sky conditions where a scene pressure is retrieved. For those conditions, the retrieved OCP should be close to the surface pressure, i.e., this difference should be small. We calculated a mean $\Delta P$ of $-1.7 \mathrm{hPa}$ and standard deviation $\sigma=46.2 \mathrm{hPa}$ using OMPS cloud retrievals from the Antarctic plateau region on 7 January 2013. The small mean value indicates that the soft calibration of TOA radiances (based on OMPS data of 21 December 2012) works well. In comparison, for OMI we find a mean $\Delta P$ of $-15.3 \mathrm{hPa}$ and $\sigma=36.0 \mathrm{hPa}$, indicating slightly lower random errors in OMI as compared with OMPS.

\subsection{Effects of the OMPS-retrieved cloud OCP on total column ozone}

The current NASA OMPS research total ozone algorithm is based on the heritage algorithm designed for the TOMS series of satellite instrument and also applied to OMI (McPeters et al., 2013). Initial studies show that the algorithm is performing with expected quality for OMPS (Kramarova et al., 2013; Flynn et al., 2014), similar to that of the well-validated OMI-TOMS algorithm (McPeters et al., 2008). The NASA OMPS total ozone algorithm currently makes use of a monthly gridded cloud OCP climatology derived from OMI-retrieved cloud OCPs. This climatology was also developed for use in the reprocessing of historical TOMS data.

Here, we compare OMPS total column ozone retrievals derived with the cloud OCP climatology and actual cloud OCPs. Figure 7 shows percentage differences between the standard NASA OMPS total ozone product and total ozone retrieved using OMPS-derived cloud OCPs. For comparison, the OMPS-derived reflectivity is also shown, indicating areas of heavy cloud cover. We note that ozone differences are very small for the overwhelming majority of the globe. Ozone differences are mostly positive and can be up to $\sim 5 \%$. They are well correlated with bright clouds over the ocean as can 

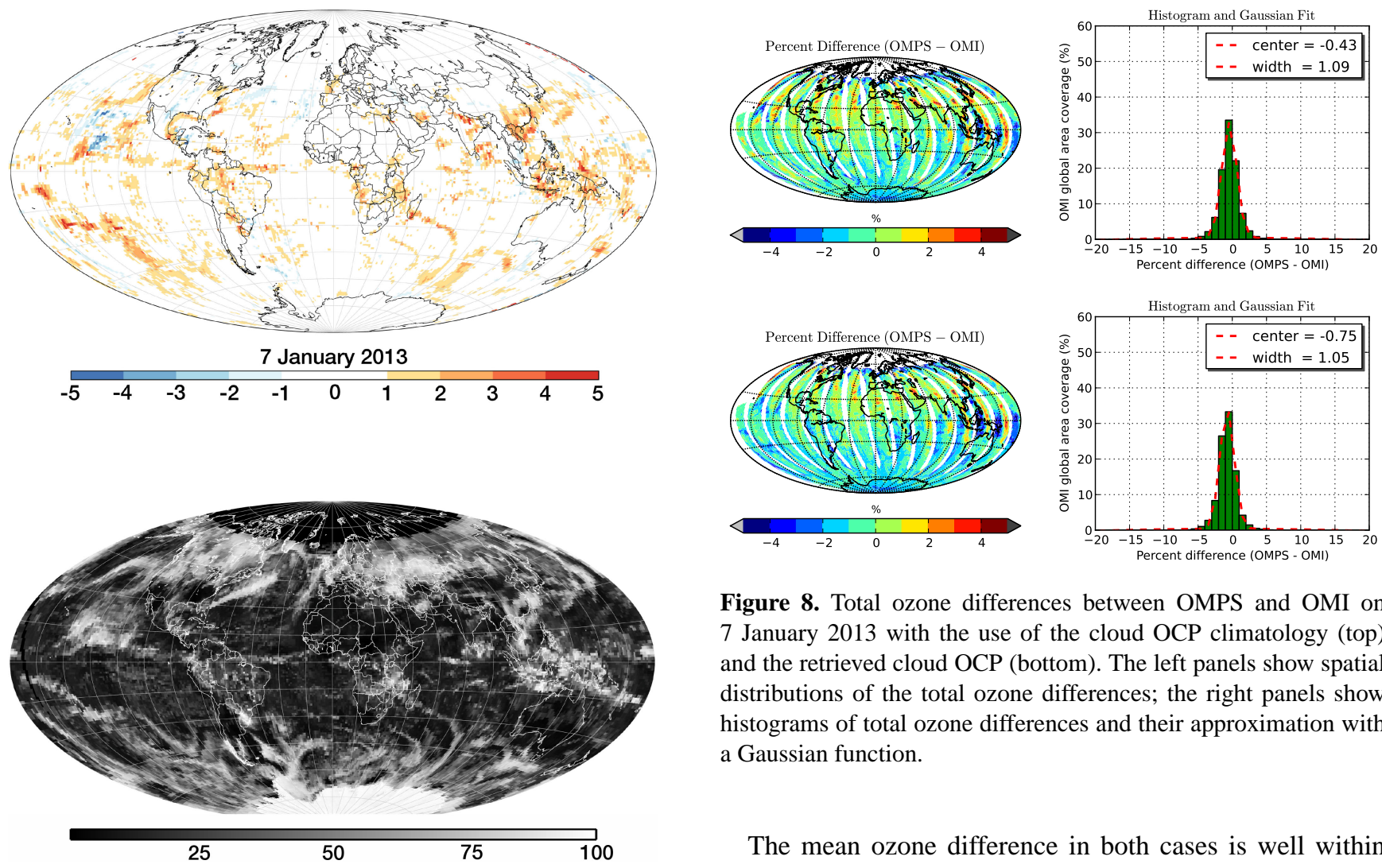

Figure 8. Total ozone differences between OMPS and OMI on 7 January 2013 with the use of the cloud OCP climatology (top) and the retrieved cloud OCP (bottom). The left panels show spatial distributions of the total ozone differences; the right panels show histograms of total ozone differences and their approximation with a Gaussian function.

The mean ozone difference in both cases is well within

Figure 7. Total ozone differences (in \%) due to the use of retrieved cloud OCPs instead of the OMI cloud OCP climatology (top) and OMPS-derived reflectivity (in \%) at $331 \mathrm{~nm}$ for 7 January 2013 (bottom).

be seen from a visual comparison in Fig. 7. Negative ozone differences over the northern Atlantic Ocean are also correlated with bright clouds. All of the total ozone differences in Fig. 7 are caused by the fact that the actual cloud OCPs deviate from the monthly gridded climatology.

Figure 8 compares OMPS and OMI total ozone retrievals where OMPS retrievals are performed with either the OMI cloud OCP climatology (top) or using actual OMPS-derived cloud OCPs (bottom). For total column ozone, having an exact match-up in both time and space is not as critical as it is for cloud retrievals. The comparison is performed for 7 January 2013 in locations not affected by the OMI row anomaly. Because the standard NASA OMPS retrievals use a different set of ozone cross sections than those used for the OMI retrievals, we reprocessed OMPS data with the Bass and Paur cross sections (Bass and Paur, 1985) used in the OMI ozone algorithm. The left panels of Fig. 8 show the spatial distribution of the percentage differences between OMPS and OMI total ozone retrievals and the right panels show histograms of those differences along with an approximation of the histograms using a Gaussian function.

$1 \%$, becoming slightly worse with the use of collocated OCP retrievals. This is most likely due to the fact that, as discussed above, the OMPS-derived OCP is higher on average than the OMI-derived OCP; this, in turn, slightly reduces the ozone retrieved by OMPS in comparison with that from OMI. However, it should also be noted that the width of the difference distribution decreases slightly when the collocated OCPs are used, from 1.09 to $1.05 \%$. Furthermore, areas with heavy cloud cover (e.g., over the Pacific Ocean and South America) visually show smaller OMPS-OMI differences in Fig. 8 when the collocated OCP retrievals are used. In those areas, reduction of the OMPS-OMI ozone differences can be up to $2 \%$.

\section{Conclusions}

We have reworked the OMI cloud OCP algorithm to handle OMPS data. Key elements of the OMPS cloud pressure algorithm include the use of soft calibration of TOA radiances, the use of a synthetic high-resolution solar flux for generation of the RRS lookup tables, and spline interpolation of the TOA radiances over the lookup table wavelength grid. We find that the PDFs of effective cloud fraction retrieved from OMPS and well-validated OMI measurements are very close to each other. Some differences in the derived ECFs are expected owing to the different sizes of the OMI and OMPS footprints. Such small differences in the PDFs of ECF are explained by the fact that a significant fraction of the OMI 
smallest-size pixels near nadir are excluded from the comparison due to the row anomaly that leads to a comparison of OMPS and OMI pixels with similar sizes. The PDFs of the OMPS and OMI OCPs are similar; however, OMPS retrieves somewhat higher OCPs on average.

The use of actual OMPS cloud OCPs, as compared with the use of an OMI-derived monthly gridded cloud OCP climatology, changes OMPS total column ozone estimates locally (presumably in the correct direction) only in areas with large differences between climatological and actual OCPs. The ozone differences can be up to $5 \%$ in such areas. However, the monthly gridded OMI cloud OCP climatology captures much of the variability in OCP. Total column ozone from OMPS appears to be quite good (by comparison with well-validated OMI retrievals) when the OMI-based cloud OCP climatology is used.

Acknowledgements. Funding for this work was provided in part by the NASA NPP Science Team for Climate Data Records program (NNH10ZDA001N) managed by Diane Wickland; we significantly leveraged our algorithm development experience funded by the NASA Aura science team. We thank P. K. Bhartia, R. D. McPeters, N. Krotkov, and K. Yang for helpful discussions. We particularly thank Jason Li for processing OMPS data used for comparisons of OMPS and OMI total ozone.

Edited by: B. Kahn

\section{References}

Ahmad, Z., Bhartia, P. K., and Krotkov, N.: Spectral properties of backscattered UV radiation in cloudy atmospheres, J. Geophys. Res., 109, D01201, doi:10.1029/2003JD003395, 2004.

Bass, A. M. and Paur, R. J.: The ultraviolet cross-sections of ozone, in: Atmospheric Ozone, edited by: Zerefos, C. Z. and Ghaz, A., D. Reidel, Norwell, Mass., 606-616, 1985.

Chance, K. and Kurucz, R. L.: An improved high-resolution solar reference spectrum for Earth's atmosphere measurements in the ultraviolet, visible, and near infrared, J. Quant. Spectrosc. Ra., 111, 1289-1295, 2010.

Dave, J. V.: Meaning of successive iteration of the auxiliary equation of radiative transfer, Astrophys. J., 140, 1292-1303, 1964.

Ferlay, N., Thieuleux, F., Cornet, C., Davis, A. B., Dubuisson, P., Ducos, F., Parol, F., Riédi, J., and Vanbauce, C.: Toward New Inferences about Cloud Structures from Multidirectional Measurements in the Oxygen A Band: Middleof-Cloud Pressure and Cloud Geometrical Thickness from POLDER-3/PARASOL, J. Appl. Meteorol. Clim., 49, 24922507, doi:10.1175/2010JAMC2550.1, 2010.

Flynn, L. E., Seftor, C. J., Larsen, J. C., and Xu, P.: The Ozone Mapping and Profiler Suite, in: Earth Science Satellite Remote Sensing, edited by: Qu, J. J., Gao, W., Kafatos, M., Murphy, R. E., and Salomonson, V. V., Springer, Berlin, 279-296, doi:10.1007/9783-540-37293-6, 2006.

Flynn, L., Long, C., Wu, X., Evans, R., Beck, C. T., Petropavlovskikh, I., McConville, G., Yu, W., Zhang, A., Niu, J., Beach, E., Hao, Y., Pan, C., Sen, B., Novicki, M., Zhou, S., and Seftor, C.: Performance of the ozone mapping and profiler suite (OMPS) products, J. Geophys. Res. Atmos., 119, 61816195, doi:10.1002/2013JD020467, 2014.

Joiner J. and Vasilkov, A. P.: First Results from the OMI RotationalRaman Scattering Cloud Pressure Algorithm, IEEE T. Geophys. Remote Sens., 44, 1272-1282, 2006.

Joiner, J., Bhartia, P. K., Cebula, R. P., Hilsenrath, E., McPeters, R. D., and Park, H.: Rotational-Raman scattering (Ring effect) in satellite backscatter ultraviolet measurements, Appl. Optics, 34, 4513-4525, 1995.

Joiner, J., Vasilkov, A. P., Flittner, D. E., Gleason, J. F., and Bhartia, P. K.: Retrieval of cloud chlorophyll content using Raman scattering in GOME spectra, J. Geophys. Res., 109, D01109, doi:10.1029/2003JD003698, 2004.

Joiner, J., Vasilkov, A. P., Yang, K., and Bhartia, P. K.: Total column ozone over hurricanes from the ozone monitoring instrument, Geophys. Res. Lett., 33, L06807, doi:10.1029/2005GL025592, 2006.

Joiner, J., Schoeberl, M. R., Vasilkov, A. P., Oreopoulos, L., Platnick, S., Livesey, N. J., and Levelt, P. F.: Accurate satellitederived estimates of the tropospheric ozone impact on the global radiation budget, Atmos. Chem. Phys., 9, 4447-4465, doi:10.5194/acp-9-4447-2009, 2009.

Joiner, J., Vasilkov, A. P., Bhartia, P. K., Wind, G., Platnick, S., and Menzel, W. P.: Detection of multi-layer and vertically-extended clouds using A-train sensors, Atmos. Meas. Tech., 3, 233-247, doi:10.5194/amt-3-233-2010, 2010.

Joiner, J., Vasilkov, A. P., Gupta, P., Bhartia, P. K., Veefkind, P., Sneep, M., de Haan, J., Polonsky, I., and Spurr, R.: Fast simulators for satellite cloud optical centroid pressure retrievals; evaluation of OMI cloud retrievals, Atmos. Meas. Tech., 5, 529-545, doi:10.5194/amt-5-529-2012, 2012.

Koelemeijer, R. B. A., Stammes, P., Hovenier, J. W., and de Haan, J. F.: A fast method for retrieval of cloud parameters using oxygen A-band measurements from the Global Ozone Monitoring Experiment, J. Geophys. Res., 106, 3475-3496, 2001.

Kramarova, N. A., Nash, E. R., Newman, P. A., Bhartia, P. K., McPeters, R. D., Rault, D. F., Seftor, C. J., Xu, P. Q., and Labow, G. J.: Measuring the Antarctic ozone hole with the new Ozone Mapping and Profiler Suite (OMPS), Atmos. Chem. Phys., 14, 2353-2361, doi:10.5194/acp-14-2353-2014, 2014.

Levelt, P. F., van der Oord, G. H. J., Dobber, M. R., Malkki, A., Visser, H., de Vries, J., Stammes, P., Lundell, J. O. V., and Saari, H.: The ozone monitoring instrument, IEEE T. Geosci. Remote, 44, 1093-1101, 2006.

McPeters, R., Bhartia, P. K., Krueger, A. J., Herman, J. R., Schlesinger B. M., Wellemeyer, C. G., Seftor, C. J., Jaross G., Taylor S. L., Swissler T., Torres, O., Labow, G., Byerly W., and Cebula R. P.: Nimbus-7 Total Ozone Mapping Spectrometer (TOMS) data products user's guide, NASA Reference Publication 1384, 1996.

McPeters, R., Kroon, M., Labow, G., Brinksma, E., Balis, D., Petropavlovskikh, I., Veefkind, J. P., Bhartia, P. K., and Levelt, P. F.: Validation of the Aura ozone monitoring instrument total column ozone product, J. Geophys. Res., 113, D15S14, doi:10.1029/2007JD008802, 2008.

McPeters, R. D., Seftor, C., Jaross, G., Li, J., Yang, K., Krotkov, N., Joiner, J., Vasilkov, A. P., and Haffner, D.: A status report to NASA headquarters of the OMPS 
science team evaluation, http://npp.gsfc.nasa.gov/DEW_NPP_ reports/OMPSNadirProductsReport(Jan-22-2013).pdf (last access: 8 September 2014), 2013.

Rozanov, V. V., Kokhanovsky, A. A., and Burrows, J. P: The determination of cloud altitudes using GOME reflectance spectra: multilayered cloud systems, IEEE T. Geosci. Remote, 42, 10091017, 2004.

Seftor, C. J., Jaross, G., Kowitt, M., Haken, M., Li, J., and Flynn, L. E.: Post-Launch performance of the Suomi NPP Ozone Mapping and Profiler, J. Geophys. Res.-Atmos., 119, 4413-4428, doi:10.1002/2013JD020472, 2014.

Sneep, M., de Haan, J., Stammes, P., Wang, P., Vanbauce, C., Joiner, J., Vasilkov, A. P., and Levelt, P. F.: Three way comparison between OMI/Aura and POLDER/PARASOL cloud pressure products, J. Geophys. Res., 113, D15S23, doi:10.1029/2007JD008694, 2008.

Spurr, R. J. D., de Haan, J., van Oss, R., and Vasilkov, A. P.: Discrete ordinate radiative transfer in a stratified medium with first order rotational Raman scattering, J. Quant. Spectrosc. Ra., 109, 404425, 2008.
Stammes, P., Sneep, M., de Haan, J. F., Veefkind, J. P., Wang, P., and Levelt, P. F.: Effective cloud fractions from the Ozone Monitoring Instrument: Theoretical framework and validation, J. Geophys. Res., 113, D16S38, doi:10.1029/2007JD008820, 2008.

Vasilkov, A. P., Joiner, J., Yang, K., and Bhartia, P. K.: Improving total column ozone retrievals by using cloud pressures derived from Raman scattering in the UV, Geophys. Res. Lett., 31, L20109, doi:10.1029/2004GL020603, 2004.

Vasilkov, A. P., Joiner, J., Spurr, R., Bhartia, P. K., Levelt, P. F., and Stephens, G.: Evaluation of the OMI cloud pressures derived from rotational Raman scattering by comparisons with other satellite data and radiative transfer simulations, J. Geophys. Res., 113, D15S19, doi:10.1029/2007JD008689, 2008.

Ziemke, J. R., Joiner, J., Chandra, S., Bhartia, P. K., Vasilkov, A., Haffner, D. P., Yang, K., Schoeberl, M. R., Froidevaux, L., and Levelt, P. F.: Ozone mixing ratios inside tropical deep convective clouds from OMI satellite measurements, Atmos. Chem. Phys., 9, 573-583, doi:10.5194/acp-9-573-2009, 2009. 